\title{
Effect of Model Height and Model Position on Forming Table on Mouthguard Thickness in Thermoforming Using Circular Frame
}

\author{
Mutsumi Takahashi ${ }^{*}$, Yogetsu Bando² \\ ${ }^{1}$ Department of Physiology, The Nippon Dental University School of Life Dentistry at Niigata, Niigata, Japan \\ ${ }^{2}$ BANDO Dental Clinic, Ishikawa, Japan \\ Email: *mutsumit@ngt.ndu.ac.jp
}

How to cite this paper: Takahashi, M. and Bando, Y. (2021) Effect of Model Height and Model Position on Forming Table on Mouthguard Thickness in Thermoforming Using Circular Frame. Materials Sciences and Applications, 12, 197-206.

https://doi.org/10.4236/msa.2021.125013

Received: April 12, 2021

Accepted: May 8, 2021

Published: May 11, 2021

Copyright $\odot 2021$ by author(s) and Scientific Research Publishing Inc. This work is licensed under the Creative Commons Attribution International License (CC BY 4.0).

http://creativecommons.org/licenses/by/4.0/

\begin{abstract}
Effectiveness and safety of mouthguards are greatly affected by its thickness. The aim of this study was to clarify the effect of model height and model position on the forming table on the mouthguard thickness in thermoforming using a circular frame. Mouthguards were thermoformed using 4.0-mm-thick ethylene-vinyl-acetate sheets and a vacuum forming machine. The sheet was sandwiched between circular frames and fixed to the clamp of the forming machine. Working models were two types of hard gypsum models trimmed so that the height of the anterior part was $25 \mathrm{~mm}$ (Model A) and $30 \mathrm{~mm}$ (Model B). The model was placed with its anterior rim positioned $40 \mathrm{~mm}$ (P40), $30 \mathrm{~mm}$ (P30), $20 \mathrm{~mm}$ (P20), or $10 \mathrm{~mm}$ (P10) from the front of the forming table. Differences in the reduction rate of the thickness due to the model height and model positions were analyzed by two-way ANOVA and Bonferroni's multiple comparison test. Differences depending on the model height were observed at P40 at the incisal edge and P30, P20, and P10 on the labial surface, and the reduction rate of the thickness was significantly smaller in Model $\mathrm{A}(P<0.01)$. As the distance from the model anterior rim to the front of the forming table was smaller, the rate of the thickness of the incisal edge and the labial surface decreases became larger. The rate of decrease in the thickness of the cusp and buccal surface was the smallest at P20. This study indicated that the difference in the thickness of the single-layer mouthguard depending on the model position on the forming table is affected by the model height. However, that is only the anterior part of the mouthguard, and the difference in thickness reduction rate is less than $5 \%$. Additionally, in order to perform stable forming, it is useful to increase the distance from the model to the frame, and it is important to position the part whose thickness is desired to be maintained in the center of the forming table.
\end{abstract}




\section{Keywords}

Mouthguard, Thermoforming, Model Height, Model Position, Thickness

\section{Introduction}

Sports mouthguard is effective in preventing and reducing injuries, and the material and thickness of the mouthguard greatly affect its effectiveness and safety [1] [2] [3] [4] [5]. Mouthguard thicknesses need more than 3 - $4 \mathrm{~mm}$ to decrease the effects of impact force [6] [7] [8] [9]. Therefore, when fabricating a custom-made mouthguard by thermoforming, it is important to understand the shape change of the sheet material that occurs during thermoforming and perform the forming operation.

During thermoforming, the thickness changes in two stages. First stage occurs when the sheet is heated by the forming machine, and the thickness of the entire sheet decreases as the softened sheet sags. Second stage occurs during vacuum or pressure forming and is affected by the form of the working model [10] [11]. Furthermore, the thickness reduction in the second stage is affected by the model position on the forming table [12]. After the model is covered with the sheet, the parts of the sheet in contact with the model and those fixed to the frame are stretched in the direction of the model during formation [10] [11] [13] [14]. Accordingly, if the length of the original sheet is insufficient for the amount of sheet deformation (i.e., the sum of the model height and the distance from the edge of the model to the sheet frame), the sheet will be stretched too much and its thickness will be reduced [14] [15]. Thus, it is predicted that the mouthguard thickness will decrease significantly where the model height is high or the distance from the model rim to the sheet frame is small.

The mouthguard sheet is either square or circular and is selected according to the shape of the sheet frame of the forming machine. However, many commercially available sheets are circular and come in a greater abundance of color variations than square sheets. Therefore, there is an auxiliary frame (circular frame) that can be used regardless of the shape and dimensions of the sheet, even for a forming machine with a square clamp frame, and the use of this auxiliary frame widens the range of suitable mouthguard sheets. With a circular frame, the distance from the model rim to the frame is shorter than that with a square frame. Therefore, the thickness reduction in the second stage of thermoforming depends on the frame shape of the forming machine, and it is predicted that it will be affected by the model form and model height.

The aim of this study was to clarify the effect of model height and model position on the forming table on the mouthguard thickness in thermoforming using a circular frame. The null hypothesis is that there is no difference in the effect on single-layer mouthguard thickness of the model position on the forming table according to the model height. 


\section{Materials and Methods}

Ethylene-vinyl-acetate mouthguard sheets (Sports Mouthguard; diameter 125 $\mathrm{mm}$, thickness $4.0 \mathrm{~mm}$, clear; Keystone Dental Inc., Cherry Hill, NJ) were used. A working model was fabricated using a silicone rubber (Correcsil, Yamahachi Dental Mfg. Co., Aichi, Japan) impression taken of a maxillary dental model (D16FE-500A-QF, Nissin Dental Products Inc., Kyoto, Japan) into which dental gypsum (New Plastone, GC Co., Tokyo, Japan) was poured. The gypsum model was trimmed using a model trimmer (MT-6; Morita Co., Tokyo, Japan): to obtain 1) a height of $25 \mathrm{~mm}$ at the incisal edge of the maxillary central incisor and a height of $20 \mathrm{~mm}$ at the mesiobuccal cusp of the maxillary first molar (Model A); and 2) heights $5 \mathrm{~mm}$ greater than model A (Model B) (Figure 1) [16]. Both models were dried thoroughly for more than $48 \mathrm{~h}$ in an air-conditioned room before use.

Mouthguards were thermoformed using a vacuum forming machine (Pro-form, T\&S Dental \& Plastics Co., Inc., Myerstown, PA). The vacuum level was 0.95 atm. The sheet was fixed to the forming machine with a circular frame (disk tray, Meinan Dental Trading Co., Aichi, Japan; $127 \times 127 \mathrm{~mm}$, diameter $110 \mathrm{~mm}$ ) [17] [18]. The model was placed with its anterior rim positioned $40 \mathrm{~mm}(\mathrm{P} 40)$, $30 \mathrm{~mm}$ (P30), $20 \mathrm{~mm}$ (P20), or $10 \mathrm{~mm}$ (P10) from the front of the forming table (Figure 2). The sheet was formed when it sagged $10 \mathrm{~mm}$ below the level of the circular frame [17]. The vacuum time was $30 \mathrm{~s}$ for all conditions. The model was left in place for at least $24 \mathrm{~h}$ before the mouthguard was removed. Six specimens were formed under each set of conditions; thus, a total of 48 mouthguards were fabricated (i.e., 2 model height $\times 4$ model positions $\times 6$ repetitions).

Mouthguard thickness after forming was measured using a specialized caliper accurate to $0.1 \mathrm{~mm}$ (21-111, YDM Co., Tokyo, Japan) without a spring, so as to prevent distortion during measurement [16] [17] [19] [20]. The measurement points were the left and right central incisors (10 points at the incisal edge and 20 points on the labial surface) and the first molars ( 8 points at the cusp and 20 points on the buccal surface) in accordance with previous studies (Figure 3) [16] [17] [19] [20]. The measurements were taken once for each specimen.
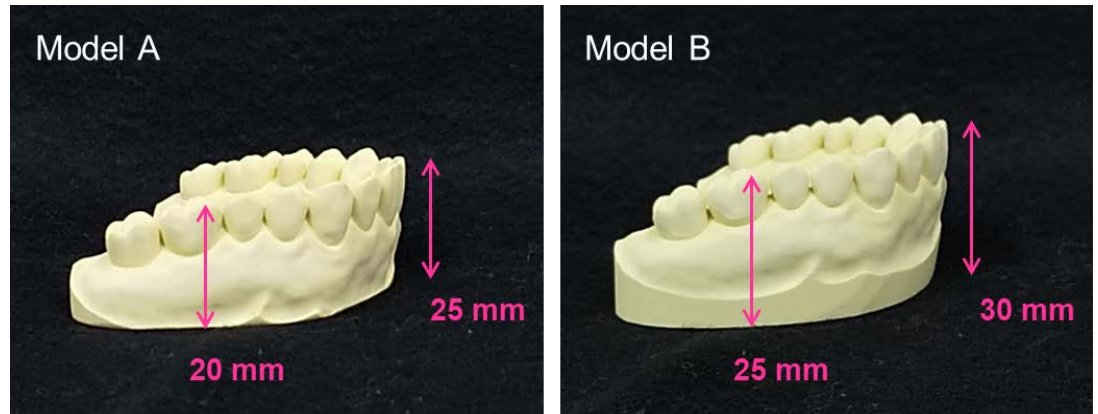

Figure 1. Working model. Model A, a height of $25 \mathrm{~mm}$ at the incisal edge of the maxillary central incisor and a height of $20 \mathrm{~mm}$ at the mesiobuccal cusp of the maxillary first molar; Model B, heights $5 \mathrm{~mm}$ greater than Model A. 


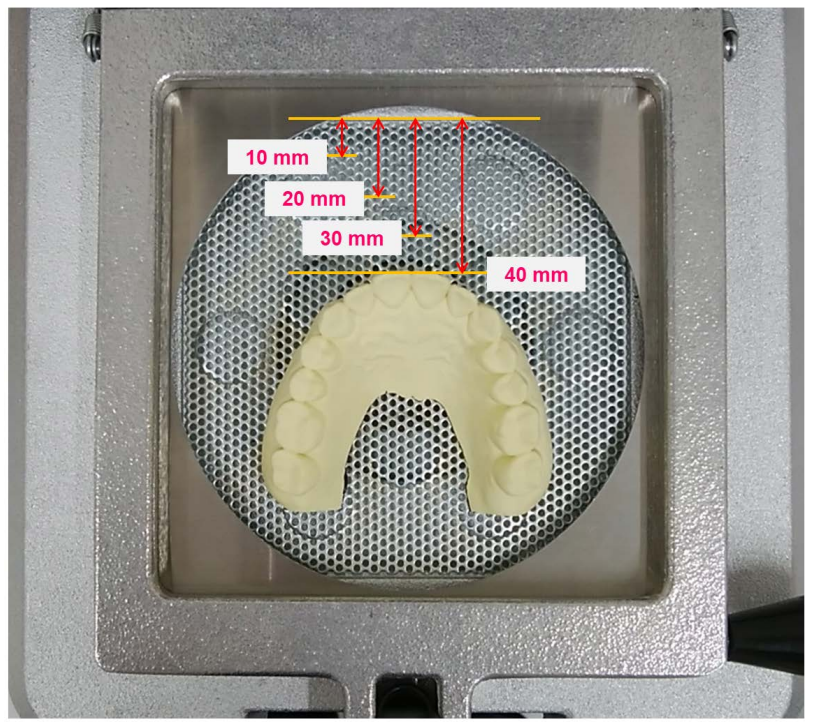

Figure 2. Model position on the forming table for the circular frame.
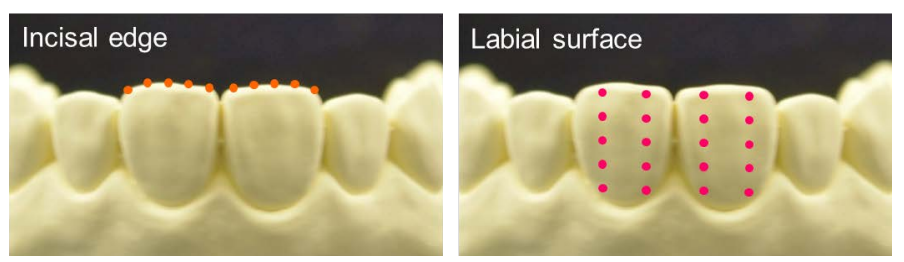

(a)
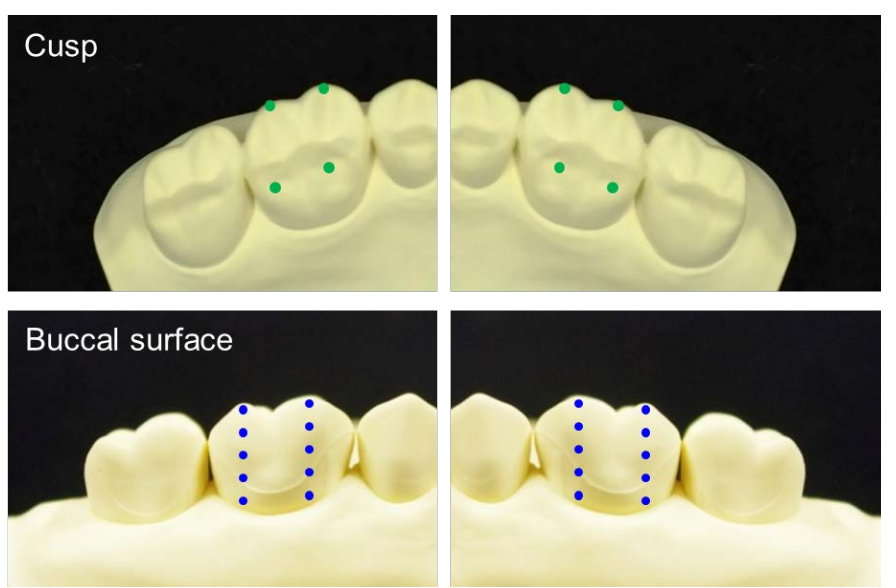

(b)

Figure 3. (a) Measurement points of the anterior teeth for the mouthguard thickness corresponding to the model (10 points on the incisal edge and 20 points on the labial surface). (b) Measurement points of the posterior teeth for the mouthguard thickness corresponding to the model ( 8 points on the cusp and 20 points on the buccal surface).

At all the measurement points, differences in the rate of thickness reduction due to model height and model positions were analyzed using statistical analysis software (IBM SPSS 24.0, SPSS Japan Inc., Tokyo, Japan). The Shapiro-Wilk test for normality of distribution and Levene's test for homogeneity of variance were also used. Each measurement exhibited normality and equal dispersion; accor- 
dingly, analysis was performed by two-way analysis of variance (ANOVA) and Bonferroni's multiple comparison test. All analytical methods were performed with a significance level of $5 \%$ and a detection power of $80 \%$, and differences were considered significant when both were satisfied.

\section{Results and Discussion}

Table 1 shows the two-way ANOVA results for the reduction rate of the thickness of the mouthguard after forming. At all measurement points, both main effects were significant, and their interaction was also significant. Based on the results, simple main effect tests were performed prior to multiple comparisons among levels.

Figure 4 and Figure 5 show the results of multiple comparison analysis. Differences depending on the model height were observed at P40 at the incisal edge and P30, P20, and P10 on the labial surface, and the rate of decrease in thickness was significantly smaller in Model A $(P<0.01)$. The difference in the thickness reduction rate depending on the model position showed the same tendency in

Table 1. Results of two-way ANOVA for thickness after formation.

\begin{tabular}{|c|c|c|c|c|c|}
\hline Source & $d f$ & SS & MS & $F$-value & $P$-value \\
\hline \multicolumn{6}{|l|}{ Incisal edge } \\
\hline Model height (A) & 1 & 20.410 & 20.410 & 199.692 & $<0.001^{* *}$ \\
\hline Model position (B) & 3 & 200.916 & 66.972 & 655.249 & $<0.001^{\star *}$ \\
\hline$A^{\star B}$ & 3 & 10.281 & 3.427 & 33.528 & $<0.001^{\star *}$ \\
\hline Error & 40 & 4.088 & 0.102 & & \\
\hline \multicolumn{6}{|l|}{ Labial surface } \\
\hline Model height (A) & 1 & 106.803 & 106.803 & 1036.926 & $<0.001^{* *}$ \\
\hline Model position (B) & 3 & 1181.087 & 393.696 & 3822.287 & $<0.001^{\star \star}$ \\
\hline$A^{\star B}$ & 3 & 15.977 & 5.326 & 51.704 & $<0.001^{\star *}$ \\
\hline Error & 40 & 4.120 & 0.103 & & \\
\hline \multicolumn{6}{|l|}{ Cusp } \\
\hline Model height (A) & 1 & 26.403 & 26.403 & 215.684 & $<0.001^{\star *}$ \\
\hline Model position (B) & 3 & 492.972 & 164.324 & 1342.333 & $<0.001^{\star \star}$ \\
\hline$A^{\star} B$ & 3 & 3.655 & 1.218 & 9.952 & $<0.001^{\star \star}$ \\
\hline Error & 40 & 4.897 & 0.122 & & \\
\hline \multicolumn{6}{|l|}{ Buccal surface } \\
\hline Model height (A) & 1 & 4.563 & 4.563 & 43.118 & $<0.001^{\star *}$ \\
\hline Model position (B) & 3 & 967.934 & 322.645 & 3048.612 & $<0.001^{* *}$ \\
\hline$A^{\star} B$ & 3 & 1.782 & 0.594 & 5.612 & $<0.01^{\star *}$ \\
\hline Error & 40 & 4.233 & 0.106 & & \\
\hline
\end{tabular}

$d f$ degree of freedom. SS: sum of squares. MS: mean square. ${ }^{* *} P<0.01$ : denotes statistically significant difference. 

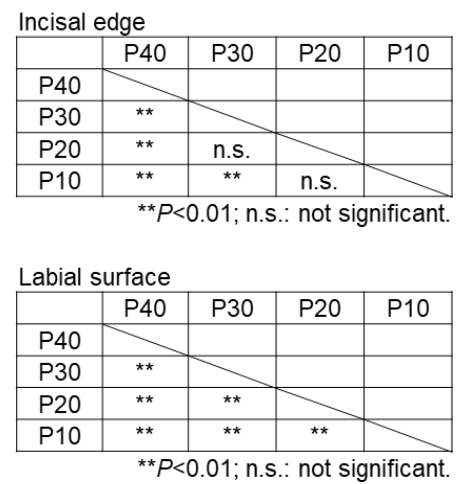

Cusp
\begin{tabular}{|c|c|c|c|c|}
\hline & P40 & P 30 & P 20 & P 10 \\
\hline P 40 & & & & \\
\hline P 30 & ${ }^{\star \star}$ & & & \\
\hline P 20 & ${ }^{\star \star}$ & n.s. & & \\
\hline P10 & n.s. & ${ }^{\star \star}$ & ${ }^{\star \star}$ & \\
\hline
\end{tabular}

Buccal surface
\begin{tabular}{|c|c|c|c|c|}
\hline & $\mathrm{P} 40$ & $\mathrm{P} 30$ & $\mathrm{P} 20$ & $\mathrm{P} 10$ \\
\hline P 40 & & & & \\
\hline P 30 & ${ }^{\star \star}$ & & & \\
\hline P 20 & ${ }^{\star \star}$ & ${ }^{\star \star}$ & & \\
\hline P10 & n.s. & ${ }^{\star \star}$ & ${ }^{\star \star}$ & \\
\hline
\end{tabular}

(a)

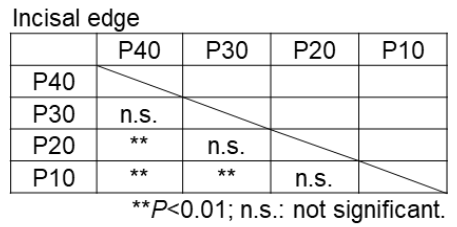

Labial surface
\begin{tabular}{|c|c|c|c|c|}
\hline & $\mathrm{P} 40$ & $\mathrm{P} 30$ & $\mathrm{P} 20$ & $\mathrm{P} 10$ \\
\hline P 40 & & & & \\
\hline P 30 & ${ }^{\star *}$ & & & \\
\hline P 20 & ${ }^{\star *}$ & ${ }^{* \star}$ & & \\
\hline P10 & ${ }^{\star \star}$ & ${ }^{\star \star}$ & ${ }^{\star \star}$ & \\
\hline
\end{tabular}

Cusp
\begin{tabular}{|c|c|c|c|c|}
\hline & P 40 & P 30 & P 20 & P 10 \\
\hline P 40 & & & & \\
\hline P 30 & ${ }^{\star *}$ & & & \\
\hline P 20 & ${ }^{* *}$ & n.s. & & \\
\hline P10 & ${ }^{\star *}$ & ${ }^{\star \star}$ & ${ }^{\star *}$ & \\
\hline
\end{tabular}

Buccal surface
\begin{tabular}{|c|c|c|c|c|}
\hline & P40 & P 30 & P 20 & P 10 \\
\hline P40 & & & & \\
\hline P 30 & ${ }^{\star \star}$ & & & \\
\hline P20 & ${ }^{\star \star}$ & ${ }^{\star \star}$ & & \\
\hline P10 & n.s. & ${ }^{\star \star}$ & ${ }^{\star \star}$ & \\
\hline${ }^{\star \star} P<0.01$; n.s.: not significant.
\end{tabular}

(b)

Figure 4. Results of Bonferroni's multiple comparison tests according to model position. (a) Model A, (b) Model B.
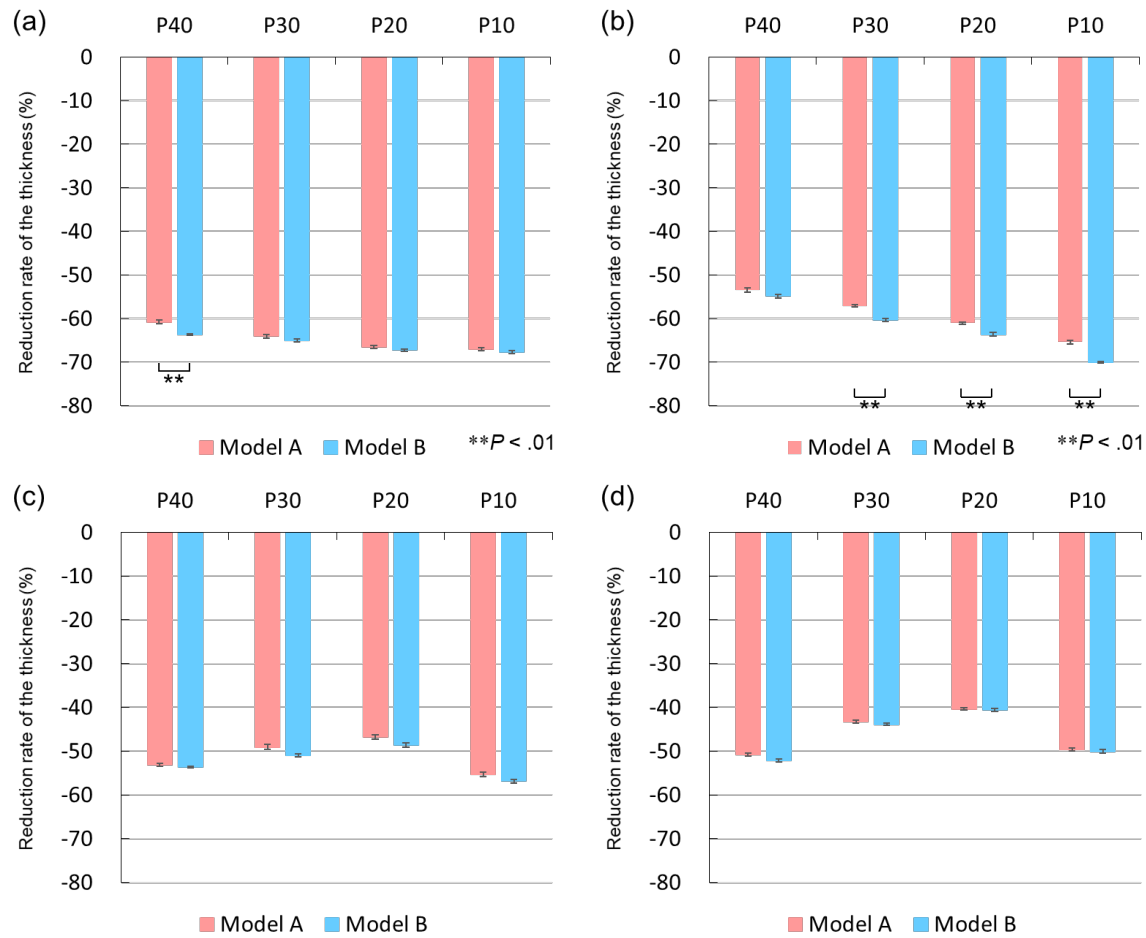

Figure 5. Mouthguard thickness at measurement points on (a) the incisal edge, (b) the labial surface, (c) the cusp, and (d) the buccal surface according to the model height and model position. Measurements are expressed as the mean \pm SD. 
both models. At the incisal edge and the labial surface, the thickness reduction rate tended to increase as the model position was moved toward the front of the forming table. In both models, P30 and P20 at the cusp and P20 on the buccal surface showed the smallest reduction in thickness $(P<0.01)$.

Fabrication methods for custom mouthguards are divided into the flasking technique, injection molding technique, and methods using forming machines [4] [10] [21] [22]. Mouthguards with the flasking technique and injection molding technique are superior in that an appropriate thickness can be obtained. Furthermore, it has been reported in a study evaluating users' subjective impressions that both are highly comfortable, and that the injection molding technique is very practical because the mouthguards are superior in their protective function [4] [21]. On the other hand, the fabrication method using a forming machine is advantageous in that the fabrication process is simple and can be fabricated without adding time-consuming processes and without requiring any special technical skills [14] [15] [16] [23]. Therefore, many clinicians use forming machines for mouthguard fabrication. However, the major drawback of thermoforming mouthguards is that the reduction in thickness after formation is remarkable at $35 \%-60 \%$ with a single layer [8] [12] [14], so it is difficult to obtain sufficient thickness with a single layer using a thermoforming machine. Thus, the desired mouthguard thickness is often achieved by lamination. However, not all athletes can use laminated mouthguards because of the high cost and longer fabrication time compared with single-layer mouthguards. For this reason, various fabrication methods and sheet shapes have been investigated to ensure the mouthguard thickness with a single layer [13] [19] [23] [24] [25] [26]. However, as a premise, it is necessary to have well-knowledge with the effect of forming conditions on the mouthguard thickness in standard thermoforming. There are many reports on factors that affect the mouthguard thickness due to thermoforming, such as the type of forming machine, model form, and the heating state of the sheet. However, there are few reports on the change in sheet thickness when using a circular frame. Therefore, this study was investigated the effects of model height and model position on the forming table on the thermoformed mouthguard thickness using a circular frame.

The results of this study showed that it was clarified that the effect of the model position on the forming table on the thickness of the single-layer mouthguard differs depending on the model height. Therefore, the null hypothesis was rejected.

It has been reported that the model shape, height, and undercut affect the thermoformed mouthguard thickness [16] [26] [27] [28]. The model height is greatest at the incisal edge and this part is where the sheet first touches the model when the sheet frame is lowered. Because the sheet is stretched with the incisal edge as the fulcrum, this area is where the thickness reduction rate is the largest. The reduction rate of the thickness at the incisal edge was about $61 \%$ for Model A and about $64 \%$ for Model B in P40, which has the smallest reduction rate of thickness, and the reduction rate of thickness increases as the model was located 
in front. On the labial surface, after lowering the sheet frame, the sheet held by the frame was stretched toward the model by suction force. From this, it was inferred that the smaller the distance from the front edge of the model to the frame than the length of the sheet pressed against the model (the anterior height of the model), the greater the rate of decrease in thickness, and which would be further affected by the model height. Therefore, the rate of decrease in thickness was the largest at P10, and the model position was forward, the greater the effect of the model height on the thickness. The difference in thickness depending on the model position was about $12 \%-15 \%$ on the labial surface in both models, which had the greatest effect on among all measurement points in this study.

On the other hand, at the posterior portion (i.e., cusp and buccal surface), there was no difference in the rate of decrease in thickness depending on the model height. It has been reported that the smooth surface and low height of the model are less affected to the mouthguard thickness [26] [27] [29], and this study also showed the same tendency. Regarding the difference in thickness depending on the model position, the rate of decrease in thickness was the smallest under the condition of P20, where the first molar as the measurement points corresponded to the anterior-posterior center of the forming table. From this, it was clarified that the reduction rate of the molar thickness of the mouthguard became smaller when the posterior portion of the model were located in the center of the forming table.

\section{Conclusion}

Within the equipment and experimental environment used in this research, this study indicated that the difference in the thickness of the single-layer mouthguard depending on the model position on the forming table is affected by the model height. However, that is only the anterior part of the mouthguard, and the difference in thickness reduction rate is less than 5\%. Additionally, in order to perform stable forming, it is useful to increase the distance from the model to the frame, and it is important to position the part whose thickness is desired to be maintained in the center of the forming table. In the future, we plan to study a forming method for certifying a mouthguard with a thickness that complies with the basic requirements $(3-4 \mathrm{~mm}$ for the labial flange) in a single-sheet thermoforming with a circular frame.

\section{Conflicts of Interest}

The authors report no conflict of interest. This study was supported by Nippon Dental University Intramural Research Fund.

\section{References}

[1] Verissimo, C., Costa, P.V., Santos-Filho, P.C., Tantbirojn, D., Versluis, A. and Soares, C.J. (2016) Custom-Fitted EVA Mouthguards: What Is the Ideal Thickness? A Dynamic Finite Element Impact Study. Dental Traumatology, 32, 95-102. https://doi.org/10.1111/edt.12210 
[2] Gialain, I.O., Coto, N.P., Driemeier, L., Noritomi, P.Y. and Dias, R.B. (2016) A Three-Dimensional Finite Element Analysis of the Sports Mouthguard. Dental Traumatology, 32, 409-415. https://doi.org/10.1111/edt.12265

[3] Bochnig, M.S., Oh, M.J., Nagel, T., Ziegler, F. and Jost-Brinkmann, P.G. (2017) Comparison of the Shock Absorption Capacities of Different Mouthguards. Dental Traumatology, 33, 205-213. https://doi.org/10.1111/edt.12324

[4] Gawlak, D., Mańka-Malara, K., Mierzwińska-Nastalska, E., Gieleta, R., Kamiński, T. and Łuniewska, M. (2017) A Comparison of Impact Force Reduction by Polymer Materials Used for Mouthguard Fabrication. Acta BioengBiomech, 19, 89-95.

[5] Tribst, J.P.M., de Oliveira, D.P.A.M., Borges, A.L.S. and Bottino, M.A. (2018) Influence of Custom-Made and Stock Mouthguard Thickness on Biomechanical Response to a Simulated Impact. Dental Traumatology, 34, 429-437. https://doi.org/10.1111/edt.12432

[6] Bemelmanns, P. and Pfeiffer, P. (2001) Shock Absorption Capacities of Mouthguards in Different Types and Thicknesses. International Journal of Sports Medicine, 22, 149-153. https://doi.org/10.1055/s-2001-11342

[7] Westerman, B., Stringfellow, P.M. and Eccleston, J.A. (2002) EVA Mouthguards: How Thick Should They Be? Dental Traumatology, 18, 24-27. https://doi.org/10.1034/j.1600-9657.2002.180103.x

[8] Geary, J.L. and Kinirons, M.J. (2008) Post Thermoforming Dimensional Changes of Ethylene Vinyl Acetate used in Custom-Made Mouthguards for Trauma Prevention: A Pilot Study. Dental Traumatology, 24, 350-355. https://doi.org/10.1111/j.1600-9657.2007.00550.x

[9] Maeda, M., Takeda, T., Nakajima, K., Shibusawa, M., Kurokawa, K. and Shimada, A. (2008) In Search of Necessary Mouthguard Thickness: Part 1 from the View Point of Shock Absorption Ability. Nihon Hotetsu Shika Gakkai Zasshi, 52, 211-219. https://doi.org/10.2186/jjps.52.211

[10] Takeuchi, M. and Togaya, N. (2006) Effectively of Thermoforming Process for Fabricating of Intraoral Apparatus. Sunashobo, Tokyo, 212-216, 33-44, 54-55, 62-67. (in Japanese)

[11] Takahashi, M., Koide, K. and Mizuhashi, F. (2014) Differences in the Thickness of Mouthguards Fabricated from Ethylene Vinyl Acetate Copolymer Sheets with Differently Arranged V-Shaped Grooves: Part 2-Effect of Shape on the Working Model. Dental Traumatology, 30, 472-476. https://doi.org/10.1111/edt.12123

[12] Takahashi, M., Araie, Y., Satoh, Y. and Iwasaki, S. (2017) Shape Change in Mouthguard Sheets during Thermoforming-Part 2: Effect of the Anteroposterior Position of the Model on Fabricated Mouthguard Thickness. Dental Traumatology, 33, 114-120. https://doi.org/10.1111/edt.12319

[13] Takahashi, M. and Koide, K. (2016) Variation in Mouthguard Thickness According to Heating Conditions during Fabrication: Part 2 Sheet Shape and Effect of Thermal Shrinkage. Dental Traumatology, 32, 185-191. https://doi.org/10.1111/edt.12209

[14] Takahashi, M., Koide, K., Satoh, Y. and Iwasaki, S. (2016) Shape Change in Mouthguard Sheets during Thermoforming. Dental Traumatology, 32, 379-384. https://doi.org/10.1111/edt.12261

[15] Takahashi, M. and Bando, Y. (2018) Effect of the Anteroposterior Position of the Model on Fabricated Mouthguard Thickness: Part 2 Influence of Sheet Thickness and Material. Dental Traumatology, 34, 370-377. https://doi.org/10.1111/edt.12423

[16] Takahashi, M. and Bando, Y. (2020) Thermoforming Technique for Suppressing Reduction in Mouthguard Thickness: Part 2 Effect of Model Height and Model 
Moving Distance. Dental Traumatology, 36, 543-550. https://doi.org/10.1111/edt.12554

[17] Takahashi, M., Koide, K. and Mizuhashi, F. (2014) Optimal Heating Conditions for Forming a Mouthguard Using a Circle Tray: Effect of Different Conditions on the Thickness and Fit of Formed Mouthguards. Journal of Prosthodontic Research, 58, 171-176. https://doi.org/10.1016/j.jpor.2014.03.005

[18] Takahashi, M., Koide, K. and Iwasaki, S. (2016) Method for Effectively Maintaining the Thickness of Mouthguards Fabricated Using EVA Sheets and a Circle Tray: Influence of Grooved Sheet and Heating Conditions. Dental Traumatology, 32, 206-211. https://doi.org/10.1111/edt.12232

[19] Takahashi, M. and Bando, Y. (2019) Thermoforming Method to Effectively Maintain Mouthguard Thickness: Effect of Moving the Model Position just before Vacuum Formation. Dental Traumatology, 35, 121-127.

https://doi.org/10.1111/edt.12447

[20] Takahashi, M. and Bando, Y. (2019) Movement of Model Position just before Vacuum Forming to Ensure Mouthguard Thickness: Part 2 Effect of Model Moving Distance. Dental Traumatology, 35, 291-295. https://doi.org/10.1111/edt.12499

[21] Gawlak, D., Mierzwińska-Nastalska, E., Mańka-Malara, K. and Kamiński, T. (2015) Assessment of Custom and Standard, Self-Adapted Mouthguards in Terms of Comfort and Users Subjective Impressions of Their Protective Function. Dental Traumatology, 31, 113-117. https://doi.org/10.1111/edt.12132

[22] Guérard, S., Barou, J.L., Petit, J. and Poisson, P. (2017) Characterization of Mouthguards: Impact Performance. Dental Traumatology, 33, 281-287. https://doi.org/10.1111/edt.12329

[23] Takahashi, M., Koide, K., Satoh, Y. and Iwasaki, S. (2016) Heating Methods for Reducing Unevenness Softening of Mouthguard Sheets in Vacuum-pressure Formation. Dental Traumatology, 32, 316-320. https://doi.org/10.1111/edt.12254

[24] Takahashi, M., Koide, K. and Mizuhashi, F. (2012) Difference in the Thickness of Mouthguards Fabricated from Step-Type Polyolefin-Polystyrene Copolymer Sheets Differently Arranged V-Shaped Grooves. Journal of Prosthodontic Research, 56, 281-286. https://doi.org/10.1016/j.jpor.2012.03.001

[25] Takahashi, M., Koide, K., Mizuhashi, F. and Sato, T. (2015) Investigation of Vacuum Forming Techniques for Reduction of Loss in Mouthguard Thickness: Part 2 Effects of Sheet Grooving and Thermal Shrinkage. Dental Traumatology, 31, 314-317. https://doi.org/10.1111/edt.12162

[26] Takahashi, M. and Bando, Y. (2021) Fabrication Method to Maintain Mouthguard Thickness Regardless of the Model Angle. Dental Traumatology, 37, 131-137. https://doi.org/10.1111/edt.12584

[27] Takahashi, M. and Bando, Y. (2021) Effect of Acute Angle Model on Mouthguard Thickness with the Thermoforming Method and Moving the Model Position just before Fabrication. Dental Traumatology, 37, 138-144.

https://doi.org/10.1111/edt.12603

[28] Takahashi, M. and Bando, Y. (2021) Effect on Thickness of a Single-Layer Mouthguard of Positional Relationship between Suction Port of the vacuum Forming Device and the Model. Dental Traumatology [Online ahead of print]. https://doi.org/10.1111/edt.12646

[29] Takahashi, M. and Bando, Y. (2020) Mouthguard Thermoforming Method to Decrease Palatal Thickness while Maintaining Labial and Buccal Thickness. Materials Sciences and Applications, 11, 370-381. https://doi.org/10.4236/msa.2020.116025 